\title{
Relações de gênero na Educação Infantil: estrutura e agência no processo de construção de sentidos sobre ser menino e ser menina
}

\section{Gender relations in Early Childhood Education: structure and agency in the process of building meanings about being a boy and being a girl}

\author{
Sandro Vinicius Sales Santos* \\ Isabel de Oliveira e Silva**
}

\begin{abstract}
RESUMO
Neste artigo, analisam-se as formas como as crianças vivenciam as relações de gênero em uma instituição de Educação Infantil, de modo a evidenciar as articulações entre as dimensões estruturais e as agências de meninos e de meninas. $\mathrm{O}$ objeto da pesquisa são as relações entre a regulação institucional e as ações de meninos e de meninas de 4 e 5 anos, nas escolhas e nos usos dos ambientes de uma instituição de Educação Infantil. Do ponto de vista teórico, o texto ancora-se nos estudos de gênero, da infância e da Educação Infantil. Já do ponto de vista metodológico, o estudo configura-se como uma etnografia desenvolvida ao longo de 2015 com 7 meninas e 11 meninos de 5 anos de idade e seus professores em uma instituição pública de Educação Infantil situada em Belo Horizonte, Minas Gerais, tendo como instrumentos de produção de dados: observação participante, entrevistas e desenhos articulados com a oralidade das crianças. Verificou-se que a regulação exercida pelos professores influencia a ação das crianças no processo de
\end{abstract}

* Universidade Federal dos Vales do Jequitinhonha e Mucuri. Diamantina, Minas Gerais, Brasil. E-mail: sandrovssantos@gmail.com - https://orcid.org/0000-0002-9666-3639

** Universidade Federal de Minas Gerais. Belo Horizonte, Minas Gerais, Brasil. E-mail: isabel.os@uol.com.br - https://orcid.org/0000-0003-2223-4548 
escolha e uso que fazem dos espaços da Educação Infantil, uma vez que os meninos se mostraram mais expansivos do que as meninas no que tange ao uso dos espaços da instituição.

Palavras-chave: Infância. Crianças. Educação Infantil. Relações de gênero. Estrutura e agência.

\begin{abstract}
In this article, the ways children experience gender relations in an Early Childhood Education institution are analyzed, in order to highlight the articulations between the structural dimensions and the agencies of boys and girls. The research object is the relations between the institutional regulation and the actions of boys and girls of 4 and 5 years old, in the choices and uses of the environments of an institution of Early Childhood Education. From a theoretical point of view, the text is anchored in gender studies and studies of childhood and Early Childhood Education. From the methodological point of view, the study is configured as ethnography developed throughout 2015 with 7 girls and 11 boys of 5 years old and their teachers in a public Early Childhood Education institution located in Belo Horizonte, Minas Gerais, Brazil, having as instruments of data production: participant observation, interviews, drawings articulated with the orality of the children. It was verified that the regulation exerted by teachers influences the action of children in the process of choice and use of the spaces of Early Childhood Education, since boys were more expansive than girls concerning the use of the spaces of the institution.
\end{abstract}

Keywords: Childhood. Children. Early Childhood Education. Gender relations. Structure and agency.

\title{
Introdução
}

Este artigo objetiva analisar os modos pelos quais as crianças produzem sentidos sobre as relações de gênero vivenciadas no interior de uma instituição de Educação Infantil ${ }^{1}$. O texto busca evidenciar como representações de

1 Os dados apresentados ao longo deste artigo compõem a tese de doutorado intitulada: "A socialização de Gênero na Educação Infantil: uma análise a partir da perspectiva das crianças", defendida em outubro de 2016 no Programa de Pós-Graduação Conhecimento e Inclusão Social da Faculdade de Educação da Universidade Federal de Minas Gerais. Agradecemos à Coordenação de Aperfeiçoamento de Pessoal de Nível Superior (Capes) pelo apoio financeiro. 
gênero ${ }^{2}$ encontram-se presentes na estruturação do ambiente da instituição, enfatizando seus efeitos sobre a agência (capacidade de ação social) das crianças. As discussões aqui presentes sustentam-se em descrições etnográficas desenvolvidas ao longo do ano letivo de 2015 com 18 crianças (sete meninas e onze meninos), a professora e o professor que com eles/as conviviam cotidianamente em uma instituição pública de Educação Infantil situada em Belo Horizonte, Minas Gerais.

No âmbito da produção científica brasileira, tem sido profícua a investigação das relações de gênero na infância, pois, nos últimos 20 anos, a área tem desenvolvido importantes estudos realizados por diferentes tradições teórico-metodológicas. Desse modo, presencia-se, nesse período, a evolução das pesquisas que abarcam a interseccionalidade de gênero e infância em, pelo menos, duas frentes de investigação distintas. De um lado, um conjunto de pesquisas analisa as pedagogias de gênero produzidas pelos adultos para as crianças (FELIPE; GUIZZO, 2003; FELIPE, 2009; SALGADO, 2012; SILVA; BERTUOL, 2014; dentre outros). Tais estudos buscam descortinar um projeto educativo taciturno e fluido ao qual nomeamos "pedagogia de gênero" (SANTOS, 2016), que procura conformar as subjetividades de meninos e de meninas, diferenciando-as por meio de um currículo e de uma didática que se pulveriza "[...] sob a forma de brinquedos, desenhos animados, filmes, revistas, canções, danças e uma série de outros produtos culturais", dispostos no âmbito das instituições de Educação Infantil (SALGADO, 2012, p. 119).

De outro lado, encontram-se as investigações que analisam as relações de gênero pela perspectiva das crianças (FINCO, 2003, 2013; SAYÃO, 2003; NEVES, 2008; KISHIMOTO; ONO, 2008; BUSS-SIMÃO, 2012, 2013; dentre outros). Esses estudos ressaltam a capacidade de as crianças lidarem, desde muito cedo, com as relações sociais que vivenciam entre si, pois, "[...] nas brincadeiras que inventam, meninos e meninas demonstram que os papéis de gênero vão sendo delineados muito cedo, embora na infância seja bastante possível transgredi-los" (SAYÃO, 2003, p. 78).

Diante das peculiaridades da produção recente do campo da educação, observa-se a ausência de estudos que busquem compreender as intrincadas dimensões que envolvem as relações de gênero na infância. Dito de outro modo, a proposição de investigações que analisem as experiências de gênero produzidas pelas crianças sem, no entanto, desconsiderar as forças estruturais que se interpõem nesse processo, conforma-se como uma lacuna da produção científica nacional.

2 As representações simbólicas de gênero são aqui compreendidas como um "conjunto de formas culturalmente organizadas que possibilitam aos sujeitos aludir, classificar, mostrar ou nomear a si mesmos, as pessoas e as coisas com base nas diferenciações historicamente construídas entre a masculinidade e a feminilidade" (SANTOS, 2017, p. 733). 
O objeto de estudo aqui analisado compreende as relações entre a regulação institucional e as ações de meninos e de meninas de 4 e 5 anos no tocante às relações de gênero e como elas interferem nas escolhas e nos usos dos ambientes de uma instituição de Educação Infantil. Nessa direção, a pergunta que orientou a pesquisa e as análises aqui discutidas consiste em: Como as escolhas e as ações de meninos e de meninas no uso dos ambientes de uma instituição de Educação Infantil se relacionam com a regulação institucional formalizada e/ou presente nas práticas das/os professoras/es e demais adultos, tendo como mediadores as relações de gênero? Dessa questão central, decorrem outras duas: Como a regulação institucional de construção e uso dos ambientes institui uma pedagogia de gênero? E como as ações das crianças se conformam e/ou transformam os usos determinados, revelando ou não sua agência e sua perspectiva sobre os ambientes da Educação Infantil e as relações que neles ocorrem?

Assim, ao reconhecermos a densidade e a complexidade constitutivas das relações sociais vivenciadas pelas crianças (que se alternam entre a dinamicidade e a interatividade inerentes às relações entre pares, ao mesmo tempo que pesa a multiplicidade de sentidos presentes nas interações com os adultos), optamos, nas linhas deste artigo, por analisar os modos como meninos e meninas significam as relações de gênero a partir de uma aproximação com seus universos de referência. Tal empreendimento nos impôs dois desafios: o primeiro, de ordem teórica; e o segundo, de ordem metodológica.

Do ponto de vista teórico, foi preciso articular aportes conceituais capazes de possibilitar a construção de olhares sensíveis às especificidades etárias das crianças. Assim, para analisar os sentidos produzidos por meninos e meninas de cinco anos de idade sobre as relações de gênero vivenciadas no interior de uma instituição pública de Educação Infantil, foi necessário articular, além de teorias e autores/as dos novos estudos da infância (THORNE, 1993; MORROW, 2006; FERREIRA, 2002; CORSARO; AYDT, 2003; CORSARO, 1997; 2011; dentre outros), autores/as dos estudos feministas e de gênero (WEST; ZIMMERMAN, 1987; CARVALHO, 2012; CONNELL; PEARSE, 2015; dentre outros/as), ratificando o entendimento de que a infância é, na atualidade, vista como um fenômeno social complexo, híbrido e multifacetado.

Já em relação às questões metodológicas, buscamos empreender uma leitura da experiência das crianças por meio da alteridade da infância. Para tanto, construímos um desenho metodológico para a investigação que permitiu descrever, com densidade (GEERTZ, 1989), as especificidades das experiências sociais de gênero das crianças. Por meio da realização de uma etnografia (SPRADLEY, 1979; GEERTZ, 1989; MAGNANI, 2002; GRAUE; WALSH, 2003) em uma instituição pública de Educação Infantil, preocupamo-nos em aceder à perspectiva das crianças com o objetivo de compreender os modos complexos e multifacetados que elas evidenciam ao vivenciar as relações de gênero. 
Para esse empreendimento, utilizamos uma diversidade de instrumentos de produção de dados (observação participante, entrevistas com adultos e crianças; desenhos, articulados com a oralidade das crianças), além das diferentes formas de registro (notas em caderno de campo, fotografias, gravações em áudio), uma vez que "[...] um bom registro de dados contém pontos de vista recolhidos de tantas perspectivas quanto possível" (GRAUE; WALSH, 2003, p. 127). A conjugação entre esses diferentes instrumentos de pesquisa permitiu-nos uma leitura interpretativa das experiências das crianças no que concerne à apropriação das relações de gênero no contexto da instituição de cuidados e de educação o que ratifica a relevância da triangulação de dados na pesquisa com crianças (GRAUE; WALSH, 2003; ROCHA, 2008).

Ao analisarmos as relações de gênero por diferentes ângulos (instrumentos) e pela perspectiva de diferentes atores (adultos e crianças), compreendemos melhor as especificidades em torno das aprendizagens relativas à construção das identidades de gênero, de forma a evidenciar que ser homem e mulher, menino e menina são construções sociais complexas e diversificadas. Esse processo consente-nos considerar as masculinidades e as feminilidades como possibilidades plurais que permitem aos seres humanos ser e estar no mundo, o que inclui, também, as próprias crianças.

Este texto está organizado em três partes. Na primeira seção, são apresentados os aportes teóricos da investigação que permitiram compreender as complexas e intrincadas relações entre gênero e infância. Na segunda seção, por meio dos dados empíricos produzidos na interlocução com as crianças e seus/suas professores/as, evidenciam-se os modos como as representações de gênero presentes no ambiente da instituição de Educação Infantil conformam-se como dimensões estruturantes das relações sociais entre adultos e crianças, com efeitos, principalmente, sobre a ação social de meninos e de meninas. Por último, tecemos algumas considerações finais.

\section{Gênero e infância; estrutura e agência: dualismos presentes nas experiências das crianças em contextos de Educação Infantil}

Virgínia Morrow (2006) afirma que, no âmbito internacional, mais precisamente no da sociologia de tradição anglo-saxã, com exceção da pesquisa educacional (que, assim como no Brasil, paulatinamente vem elevando o quantitativo de investigações), pouca atenção tem sido dada às crianças no que concerne à construção de suas identidades de gênero (MORROW, 2006). Para a 
autora, as pesquisas sociológicas, ao buscarem demonstrar certa regularidade nas experiências de gênero de meninos e de meninas, comumente incorrem no erro da generalização, isto é, da universalização de discursos sobre as experiências produzidas e vivenciadas por meninos e meninas.

Para Morrow (2006), as categorias constituintes da identidade, tais como classe social, idade, etnia, religião, dentre outras, se amalgamam, influenciando as infâncias das crianças e, consequentemente, suas identidades de gênero. Esse fato evidencia a insuficiência de teorizações que insistem em universalizar ou idealizar o fenômeno da infância (MORROW, 2006).

O reconhecimento da complexidade dos contextos de ação nos quais as crianças atuam também tem permitido lançar novas luzes sobre a agência (capacidade de ação) de meninos e de meninas. Se as relações sociais vivenciadas na companhia dos adultos são atravessadas, em sua grande maioria, por sentidos controversos e quase sempre produzidos unilateralmente (do adulto para a criança), no âmbito das relações com os pares, meninos e meninas criam, negociam e constroem ativamente novos sentidos sobre as relações de gênero (THORNE, 1993; MORROW, 2006; CORSARO; AYDT, 2003; CORSARO, 2011). Assim sendo, as relações sociais de gênero, que são construídas e apreendidas pelas crianças na articulação com os adultos, são constantemente confrontadas, interpretadas e negociadas nas relações que elas estabelecem com seus pares.

Apesar de haver diferentes acepções e tradições teóricas dentro do pensamento feminista (CARVALHO, 2012), é preciso tomar o gênero em uma acepção peculiar, qual seja: compreendendo-o como uma performance cotidiana que é recorrentemente aberta à reflexão e ao questionamento (THORNE, 1993). Trata-se, pois, de uma construção que, embora subjetiva, é simultaneamente sistemática, recorrente e estabelecida de modo interpessoal (CONNELL; PEARSE, 2015). A compreensão pessoal do gênero decorre de uma multiplicidade de processos nos quais os indivíduos constroem-se como homens e mulheres; meninos e meninas, ao passo que, nas situações cotidianas, constroem também as relações de gênero.

Neste texto, portanto, compreendemos o gênero como consequência da conjugação de inúmeras unidades de sentido, cultural e estruturalmente produzidas, sobre e a partir dos modos como os corpos são socialmente significados, ao mesmo tempo que são concomitantemente construídos (THORNE, 1993; WEST; ZIMMERMAN, 1987; CONNELL; PEARSE, 2015). Dessa maneira, no contexto da Educação Infantil - espaço social estruturado pelo adulto para as crianças -, as representações de gênero colocam-se como dimensão estruturante das relações sociais. O gênero é, assim, compreendido como uma estrutura social que possui dimensões específicas, pois enfoca uma multiplicidade de práticas culturais que regulam, adéquam e ajustam as 
diferenciações entre os corpos - de homens e de mulheres; de meninos e de meninas (CONNELL; PEARSE, 2015). Não obstante, é necessário reconhecer que existe uma diversidade de outros modos de ser e de estar no mundo que ultrapassam esse dualismo (SANTOS, 2018).

Nessa perspectiva, Manuela Ferreira (2002) sugere que a oferta de brinquedos leva as crianças a erguerem verdadeiras fronteiras gendradas, estruturalmente demarcadas. Dessa maneira, o estabelecimento de territórios limítrofes, nos quais elas brincam de modo segregado em grupos distintos, que associam as meninas ao espaço da casinha e direciona os meninos aos brinquedos mais ousados (armas, carros, dentre outros), faculta "[...] a construção de fronteiras bipolares de acordo com uma identificação de interesses de género contrastantes, extremados e exclusivos" (FERREIRA, 2002, p. 128).

Para a autora, a pertença específica das crianças em terrenos privativos de relações pautadas no binarismo masculino/feminino possibilita a criação de grupos “[...] homossociais de género, relativamente segregados: o das meninas e o dos meninos" (FERREIRA, 2002, p. 128). Na relação entre os grupos de meninos e de grupos de meninas (relações heterossociais), as crianças erguem verdadeiras "fronteiras" nas quais trabalham ativamente na compreensão das relações de gênero ao mesmo tempo que as vivenciam (FERREIRA, 2002, p. 127). Segundo a autora:

Trata-se afinal do contínuo trabalho de fronteira das relações entre género (cf. Thorne, 1993:64-88; Louro, 1997:79; Corsaro 1997:182; Danby, 1998:198) que marca e reforça as diferenças e separações entre grupos, pelo que a construção de relações homossociais, ao erguer fronteiras de género exclusivas define também como é que as relações heterossociais são construídas e mantidas (FERREIRA, 2002, p. 127-128, grifos da autora).

As considerações de Ferreira (2002) demonstram, no que concerne ao gênero, que elementos estruturantes das relações sociais têm efeitos sobre a ação das crianças. Contudo, faz-se necessário articular novas lentes teóricas que permitam uma análise interpretativa capaz de evidenciar as interfaces entre estrutura e agência no âmbito da socialização de gênero ${ }^{3}$ na Educação Infantil.

3 A socialização de gênero consiste na conjugação de diferentes processos socializadores com vistas a produzir sujeitos gendrados. Na articulação de tais processos de socialização, as crianças, na qualidade de sujeitos ativos, interagem com os adultos, com seus pares, com a cultura e com a sociedade a partir de um quadro de referências, ambíguo, conflituoso e, por vezes, contraditório (SANTOS, 2016, 2017, 2018). 
Connell e Pearse (2015) buscam compreender os modos pelos quais a agência (que transcorre por meio de práticas corporais) e as estruturas sociais se interconectam pelo tempo. Segundo as autoras, as relações de gênero "[...] somam-se ao processo histórico no qual a sociedade é corporificada e os corpos são arrastados para a história", percurso que elas nomeiam como corporificação social, uma espécie de "prática corporal reflexiva", no caso das condutas sociais, em que os corpos são simultaneamente agentes e objetos (CONNELL; PEARSE, 2015, p. 112).

Nessa perspectiva, as masculinidades e as feminilidades são construtos socialmente elaborados com os quais convivemos desde a mais tenra idade, pois, a partir do nascimento (ou até antes dele), vivenciamos diversos processos de socialização que visam à fabricação de sujeitos gendrados, em que diferentes códigos, agenciamentos e estruturas sociais (generificadas) nos são impostos. Assim, os modos pelos quais nos tornamos sujeitos de gênero procedem da conjugação de inúmeros processos de socialização, repletos de tensões e de ambiguidades, nos quais os sujeitos fabricam a si próprios a partir das condições objetivas (estruturais) que lhes são dadas (CONNELL; PEARSE, 2015).

No âmbito da sociologia, o conceito de estrutura tem sido convocado para demonstrar a existência de regularidades (padrões) nas ações e nas relações sociais. Segundo Connell e Pearse (2015), as relações sociais entre os indivíduos teriam pouco significado e, consequentemente, pouca durabilidade e permanência se fossem transitórias e irregulares. Para elas, "[...] a duração e os padrões extensivos entre as relações sociais são o que a teoria social chama de estrutura" (CONNEL; PEARSE, 2015, p. 156). Nesse sentido, os arranjos de gênero de uma sociedade se conformam como uma estrutura social que organiza e é organizada pelas relações sociais de meninos e de meninas; de homens e de mulheres.

Nesse sentido, é preciso considerarmos, entretanto, que as estruturas não são apenas coercitivas e reguladoras da agência humana; elas também podem impulsionar a ação (CONNEL; PEARSE, 2015). Assim, de um modo ou de outro - seja por meio do alinhamento da ação com a coerção social imposta pelas estruturas, seja pela via da crítica realizada pelo sujeito sobre essas estruturas na construção de suas experiências -, o que está em voga é que, de algum modo, as estruturas se relacionam com a ação dos indivíduos. Nos dizeres de Connell e Pearse (2015, p. 157), “[...] uma estrutura das relações não decide mecanicamente como as pessoas ou os grupos agem. [...]. Mas uma estrutura de relações certamente define possibilidades para ação e suas consequências". Segundo as autoras: 
A estrutura social condiciona a prática. No entanto, estruturas não são anteriores à vida cotidiana. Estruturas sociais são atualizadas (tornadas ato) pela atividade humana ao longo do tempo e historicamente criadas. Relações de gênero são atualizadas quando continuamos nos envolvendo em "modos de comportamento generificados", como Carol Hagemann-White (1987) menciona. Estrutura e mudança não são opostas, mas sim partem da mesma dinâmica de nossa vida social (CONNELL; PEARSE, 2015, p. 157).

Ao analisarem o gênero por essa chave teórica, as autoras compreendemno como um modo específico de corporificação social, isto é, como forma de conexão dos processos corporais às estruturas sociais. Para elas, a propriedade distintiva do gênero pressupõe que ele faz menção, concomitantemente, às estruturas corporais e aos processos ligados à reprodução humana, já que se trata de um construto teórico que abarca um conjunto de práticas sociais que incluem "[...] cuidados com crianças, parto, interação sexual - que mostram as capacidades de corpos humanos de parir, dar leite, dar e receber prazer sexual. Só podemos começar a entender o gênero se compreendermos o quão próximo os processos sociais e corporais se encontram" (CONNELL; PEARSE, 2015, p. 113).

Tais capacidades corporais e as práticas pelas quais são realizadas constituem uma arena, "[...] um campo corporal em que algo social acontece" (CONNELL; PEARSE, 2015, p. 113). Entre esses acontecimentos, estão as categorias culturais "homem" e "mulher" - e todas as outras categorias de gênero que uma dada sociedade defina, tais como: meninos e meninas, agressividade e docilidade; masculinidade e feminilidade, brutalidade e sensualidade, dentre outras) e "[...] isso pode ser chamado de 'arena reprodutiva' na vida social" (CONNELL; PEARSE, 2015, p. 113).

Considerando a instituição de Educação Infantil como um espaço socialmente organizado, regulado e constantemente estruturado pelos/as adultos/ as para as crianças, estas, ao agirem nesse contexto, muitas vezes se deparam com situações cujas representações de gênero promovem influências sobre suas agências, que ora aceitam, conformam e alinham suas ações a tais regulações, ora as refutam, construindo novas e variadas possibilidades de vivenciar as masculinidades e as feminilidades. 


\section{Compreendendo como estrutura e agência se articulam nas aprendizagens de gênero das crianças}

A inserção prolongada na Instituição de Educação Infantil, contexto de referência em que crianças e adultos cotidianamente conviviam, evidenciou a existência de diferentes representações sobre as masculinidades e sobre as feminilidades cuja presença tinha efeitos sobre a agência dos indivíduos, principalmente, sobre os/as pequenos/as. Conforme dito, o gênero conforma-se como uma estrutura da sociedade cuja organização vincula a agência humana às dimensões estruturantes, evidenciando que as aprendizagens referentes às masculinidades e às feminilidades se dão em uma arena reprodutiva - campo de ação corporal no qual a reprodução societal é garantida pela socialização das novas gerações, processo nomeado como "corporificação social" (CONNEL; PEARSE, 2015).

Como sugere Spradley (1979), a etnografia conforma-se como a "[ $\ldots]$ descrição de um sistema de significados culturais de um determinado grupo [...]" e, desse modo, seu objetivo principal consiste em compreender um outro modo de vida, apreendido, porém, do ponto de vista mais próximo possível ao dos informantes. $\mathrm{O}$ trabalho de campo etnográfico, nessa perspectiva, abarca o estudo do que o mundo é (ou do que ele possa vir a ser) na visão dos nativos. Assim sendo, a etnografia objetiva descrever como as pessoas veem, ouvem, falam, pensam e agem no e sobre o mundo - práticas culturais que, do ponto de vista das relações de gênero, são apreendidas ao mesmo tempo que são vivenciadas no fluxo cotidiano da vida (THORNE, 1993; WEST; ZIMMERMAN, 1987; CONNELL; PEARSE, 2015).

Nesse sentido, o contato prolongado com os sujeitos (adultos e crianças) possibilitou uma aproximação com seus universos de referências, evidenciando, de igual modo, a existência de processos de apropriação distintos, por parte das crianças, dos espaços da instituição de Educação Infantil. Os meninos, quando brincavam, expressavam a necessidade de expandir suas interações e suas brincadeiras pelo espaço, extrapolando, muitas vezes, os domínios da sala de referência e ocupando outros ambientes da instituição. Já as meninas, comumente, permaneciam brincando dentro da sala, fato que pode ser visualizado no episódio descrito a seguir:

Logo após o café, a turma retorna à sala de referência para a continuidade das experiências com a linguagem matemática que foram propostas pela professora. Vânia, a docente responsável pela turma, havia terminado a 
atividade de matemática junto às crianças e lhes deu massinha de modelar para que pudessem brincar. Nesse momento, o professor Anselmo adentra a sala e explica à colega como haviam ficado os relatórios sobre as crianças que ele tinha iniciado (relatórios esses que comumente são produzidos ao final do semestre). A professora Vânia, como sempre faz, pediu-me de modo bem discreto que olhasse a turma enquanto ela iria, juntamente a Anselmo, ver tais relatórios no computador da sala dos professores. Logo que Vânia sai, Jonatas - um dos meninos da turma - pega sua massinha de modelar e coloca no potinho. Retorna à mesa e pergunta a Vitório se queria brincar de super-herói. Vitório aceita o convite e também guarda sua massinha. Em seguida, Saulo também realiza o mesmo procedimento. Não demorou muito e a maioria dos meninos presentes (Vitório, Jonatas, Gleisson, Saulo, Carlos, Gabriel, Israel, dentre outros) estava correndo pela sala com suas capas de super-heróis (pedaços de TNT cortados pela professora). As meninas permaneceram sentadas brincando com a massinha. Como já se aproximava do horário dos cantinhos, quando Vânia retornou à sala, os meninos imediatamente, sem pedir a permissão da professora, se colocaram ao lado de fora da sala para brincarem. As meninas, ainda sentadas com a massinha, pegam algumas panelinhas e passam a brincar de comidinha, como de costume (Notas do caderno de campo, 22 de junho de 2015).

Ao perceberem que a professora havia saído da sala, os meninos (liderados por Jonatas) deixaram a massinha de modelar - atividade que habitualmente as crianças realizavam sentadas - e passaram a brincar de super-heróis correndo por todo o espaço da sala de aula. Ao perceberem que a professora havia voltado, os meninos que corriam euforicamente, se agarrando e se debatendo, passaram a brincar do lado de fora, correndo e pulando por toda a extensão do corredor. As meninas, por seu turno, paulatinamente também deixaram a brincadeira com massinha de modelar, mas preferiram brincar com as panelinhas, em sala.

A Instituição de Educação Infantil é um contexto de ação regulado pelos adultos. No entanto, observa-se que, em sua dinâmica, existem situações em que as experiências podem e devem ser "[...] geridas por decisões tomadas pelas próprias crianças conforme situações que ocorrem ou são desencadeadas por elas" (SANTOS; SILVA, 2016, p. 139). No episódio descrito anteriormente, a saída da professora da sala é um desencadeador de ações de iniciativa das crianças que revelam a possibilidade de desenvolver certo senso de autonomia. Todavia, no que concerne ao gênero, observam-se diferenças nos modos de ação de meninos e de meninas que incidem sobre as formas também distintas de apropriação e uso dos espaços da instituição de Educação Infantil. 
A recorrência de episódios como esse impôs, no processo de análise, a necessidade e a urgência de revisão intensa dos registros em caderno de campo. Para além das fronterias erguidas no âmbito das brincadeiras por meio da cartografia gendrada imposta pelos brinquedos (THORNE, 1993; FERREIRA, 2002), o episódio revela as diferentes agências assumidas por meninos e meninas frente à seguinte questão: eles quase sempre partiam para a brincadeira no corredor (do lado de fora da sala); elas ficavam sentadas brincando com as panelinhas. Nesse momento, percebemos que as crianças assumiam, em suas ações, posicionamentos de gênero que envolviam as dicotomias meninos/ homens/espaços públicos/externos e meninas/mulheres/espaços privados/ internos. O que possibilitava essa diferença entre as ações de meninos e de meninas? Por que eles buscavam ampliar os espaços de brincadeiras enquanto elas preferiam ficar na sala de referência da turma? Será apenas influência dos brinquedos? Em que medida outros processos de produção de significados se interligavam a situações como estas, nas quais as separações entre meninos e meninas se davam quase que de modo "natural"?

Ao rever as anotações do caderno de campo e demais dados produzidos por meio da empiria (entrevistas com crianças e adultos, algumas fotografias e os desenhos produzidos pelas crianças), percebemos que existiam diversas situações no cotidiano da instituição que promoviam não só a separação entre meninos e meninas, mas permitiam que eles se mantivessem nos espaços externos e elas no espaço interno da sala de referência. Nesse processo, embora não fosse o único fator a contribuir para a diferenciação entre as agências de meninos e de meninas, a cartografia genderizada dos brinquedos promovia uma separação entre eles e elas, o que não passava despercebido pelas crianças. Isso se torna evidente nas entrevistas com os/as pequenos/as, pois, quando perguntadas sobre onde era melhor para brincar, as crianças demonstraram:

Quando a brincadeira é nos cantinhos, acho que não acontece isso de brincar junto não. Esse negócio de misturar pecinha com boneca lá na sala não vale muito, porque a professora não deixa misturar os brinquedos. Ou a gente brinca com pecinha ou brinca com as bonecas. Ai as meninas brincam mais com as comidinhas e os meninos mais com eles mesmos. A gente só junta no parquinho. Lá todo mundo brinca junto (Andreia Juliane, 15 de setembro de 2015).

No parquinho a gente brinca mais misturado: menino e menina misturam mais. Na sala é menino com menino e menina com menina (Cristiano, 21 de setembro de 2015). 
Como na sala de referência as crianças se encontram envolvidas por brinquedos e diversos outros artefatos que possibilitam a separação entre meninos e meninas, eles/as demonstram compreender que tais fatores influenciam suas interações, o que fica nítido na fala de Cristiano quando afirma que "na sala é menino com menino e menina com menina". O contrário se dá nos momentos de brincadeiras no parquinho que, por possuírem brinquedos menos estruturados, isto é, com menores conotações de gênero do que aqueles encontrados na sala, esse ambiente proporciona interações mais equânimes do ponto de vista das relações de gênero, nas quais meninos e meninas brincam indistintamente, pois, conforme Ana Julia, "lá [no parquinho] todo mundo brinca junto".

As fotografias de momentos de interação entre as crianças (Figura 1), tanto na sala de referência (ou em outros espaços da instituição em que as situações eram cadenciadas pelo/a professor/a) quanto no parquinho, evidenciam essa distinção: relações mais segregadas entre meninos e meninas nos espaços internos e relações mais compartilhadas entre eles/as nos espaços externos:

\section{FIGURA 1 - DIFERENTES SITUAÇÕES EM QUE AS CRIANÇAS SE UNEM E SE} SEPARAM
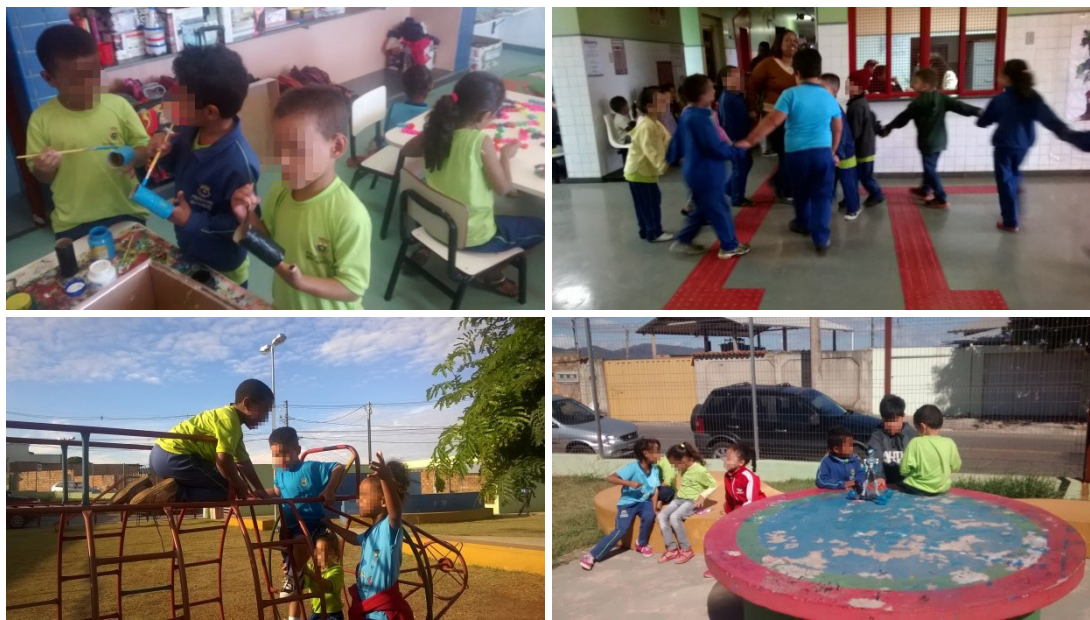

FONTE: Arquivos da pesquisa.

Percebe-se, nas falas das crianças assim como nas fotografias produzidas como registro da observação participante, que as rotinas vivenciadas na sala de referência pelo grupo, em função dos brinquedos ali dispostos e oferecidos a elas, as conduzem a construir verdadeiras fronteiras entre os gêneros que são 
erguidas nos momentos de brincadeira, o que ocorre com menor frequência no ambiente do parquinho que possui brinquedos menos estruturados do ponto de vista das relações de gênero.

Para Manuela Ferreira (2002), a disposição de brinquedos gendrados faz com que as crianças criem uma sequência de rotinas e de brincadeiras que, baseadas em elementos do mundo adulto, se configuram como legítimos territórios específicos dos grupos homossociais (de brincadeiras de meninos e de brincadeiras de meninas). De acordo com a autora, as crianças não constroem essas divisões aleatoreamente; pelo contrário, eles/as têm compreensão não só da existência, mas também da extensão dessas fronteiras. Segundo a autora, as crianças

[...] têm a noção de que há espaços, objectos e atividades "próprias" para meninas e para meninos, cuja definição do permitido e do interdito, as fronteiras, em grande parte reforçadas ou constituídas através do brincar entre si e com os/as outros/as, lhes/nos permitem compreender como elas se tornam, pertencem e veem como membros um grupo de género particular através de duas categorias relacionais (FERREIRA, 2002, p. 128).

Como forma de apreender as diferentes agências de meninos e de meninas nos momentos de brincadeiras, os/as professores/as foram entrevistados/as, possibilitando a contrução de um conjunto de dados que contribuiu para a compreensão dos sentidos coletivos construídos em torno das masculinidades e das feminilidades naquele contexto. Ao serem perguntados/as sobre como percebiam as brincadeiras de meninos e de meninas, a professora e o professor apresentaram opiniões divergentes. Anselmo afirmou não perceber diferenças entre a forma como meninos e meninas brincam na Unidade Municipal de Educação Infantil (UMEI). Para ele, os/as pequenos/as brincam indistintamente. Contudo, Vânia, que convivia com as crianças a maior parte do dia (aproximadamente três horas), não só percebe que meninos e meninas brincam de modos distintos, como apresentam comportamentos também diferenciados. Segundo o professor e a professora:

A partir do momento em que os meninos se juntam com as meninas as brincadeiras, as atitudes de uns com os outros não mudam. Com exceção das brincadeiras de lutas dos meninos - que ai eles param. Por exemplo, se as meninas estão na casinha, os meninos se aproximam e vão para a casinha (Professor Anselmo, 6 de outubro de 2015). 
Eu já percebo que as meninas são mais cautelosas. É como se elas fossem mais contidas. Tanto é que os meninos se apropriaram do espaço do corredor no momento dos cantinhos, que é um espaço grande e um espaço bom. Em momento nenhum, as meninas chegaram para mim e questionaram: "oh professora, por que você só deixa os meninos brincar no corredor? Não fui eu que deixei, foram eles que foram conquistando o espaço (Professora Vânia, 6 de outubro de 2015).

Diversas situações observadas no âmbito do trabalho de campo evidenciaram a separação entre meninos e meninas nas práticas pedagógicas e em diversos rituais que compõem a rotina da instituição de Educação Infantil. As observações revelaram que a sala de referência dispunha de brinquedos que favoreciam a separação entre meninos e meninas. No entanto, no trecho anterior, observa-se que a professora Vânia, professora de referência daquele grupo de crianças, interpreta a apropriação dos espaços externos pelos meninos como menor submissão deles à regulação adulta, positivando suas ações como conquistas. Muitas das práticas pedagógicas vivenciadas por adultos e crianças, naquele contexto, encerravam sentidos sobre as masculinidades e as feminilidades que não parecem ser objetos de reflexão por parte da professora ou do professor. Isso porque "[...] no conjunto das experiências das educadoras na instituição de Educação Infantil, há um dinamismo que expressa diferentes concepções em diferentes tempos e espaços institucionais e de relações com as crianças" (SILVA; LUZ, 2010, p. 29).

A observação em campo tornou perceptível também que, por meio dos imprevistos e das novidades surgidos na e em decorrência da vida cotidiana, representações de gênero eram constantemente reforçadas no trabalho pedagógico desenvolvido pelos/as adultos/as da instituição de Educação Infantil. O episódio a seguir ilustra como, no âmbito da instituição de cuidado e de educação, a dicotomia público/privado, reproduzida no desenrolar de uma situação vivenciada pelas crianças, explica de que forma se instaura uma lógica de uso dos espaços físicos nos momentos de brincadeiras, que permite e consente a construção de agenciamentos diferenciados: aos meninos, o uso e a circulação do e no espaço externo da instituição; e às meninas, o uso e a permanência do e no espaço interno da sala de referência: 
Já se aproxima das $8 \mathrm{~h} 30 \mathrm{~min}$ e o professor Anselmo chega à sala para que a professora Vânia possa sair de $\mathrm{ACPATE}^{4}$. O professor organiza uma atividade que consiste em criar adereços para ornamentar uma caixa de papelão onde ele guarda alguns de seus materiais. Ele explica que a caixa, sem decoração alguma, está muito feia e que, para decorá-la, precisaria da ajuda das crianças. Falou que enquanto as meninas, sentadas em sala, pintariam alguns CDs, os meninos, sentados do lado de fora, fariam alguns desenhos que seriam colados na caixa. Depois a situação se inverteria: os meninos viriam pintar na sala e as meninas iriam desenhar do lado de fora (Notas do caderno de campo, 12 de março de 2015).

Há, aqui, a presença da representação que expressa uma lógica binária de gênero que pressupõe a presença dos meninos no espaço externo, já que eles foram levados pelo professor para realizar a tarefa no corredor (do lado de fora da sala de referência da turma), fazendo com que, contrariamente, as meninas realizassem uma segunda parte da mesma tarefa dentro do espaço da sala. Havia uma promessa, por parte do professor Anselmo, de que a situação, em seguida, se inverteria: as meninas desenhariam do lado de fora da sala, e os meninos pintariam os CDs dentro de sala, o que, de fato, não ocorreu.

Ações como essa fazem com que meninos e meninas interiorizem, desde cedo, que a dicotomia público/privado regula a ação social de homens e de mulheres, considerando os primeiros mais objetivos/expansivos e que, portanto, são desde cedo conduzidos e estimulados a atuar nos domínios dos espaços públicos (considerados espaços da produção econômica e da política), enquanto as últimas, concebidas como mais subjetivas/recatadas, devem ser as responsáveis pelos afazeres do espaço privado (onde se passam os cuidados com a família e as situações relativas à intimidade). Tal afirmação fica mais nítida ao percebermos como essa lógica binária regula a agência de meninos e de meninas frente às demandas de outra tarefa proposta pela professora e que, de certo modo, vai se corporificando no fluxo da vida cotidiana (THORNE, 1993; WEST; ZIMMERMAN, 1987; CONNELL; PEARSE, 2015).

4 No contexto da rede de Ensino de Belo Horizonte, as Atividades Coletivas de Planejamento e Avaliação do Trabalho Escolar (ACPATE) consistem em situações de planejamento semanal que correspondem a 1/3 da jornada diária de acordo com a Lei No 7.577/1998. Segundo Mércia Noronha Pinto, esse tempo destinado ao estudo, planejamento e avaliação do trabalho cumpre a determinação da LDB e da Lei N$^{\circ} 11.738 / 2008$ (PINTO, 2014). 
Em função do grande número de meninos, a professora Vânia, constantemente os incentivava a brincar fora da sala de aula (uma vez que a docente os via como mais agitados e irrequietos do que as meninas e suas brincadeiras costumavam ser repletas de correria e algazarra). Sem perceber, ao fazer essa separação, a professora contribuía para a divisão das crianças ao permitir que os meninos brincassem do lado de fora. Desse modo, no que concerne à apropriação dos espaços (e também à apropriação das relações de gênero), meninos e meninas o faziam de modos distintos, reproduzindo, em certo sentido, as lógicas dicotômicas disseminadas pelos professores; corporificando a estruturação do contexto social (CONNELL; PEARSE, 2015), nesse caso, da instituição de Educação Infantil. Isso pode ser visualizado no episódio a seguir:

Nos momentos dos cantinhos, os professores constantemente colocavam os meninos que queiram brincar de carrinho ou de super-herói para fazê-lo no corredor. Percebendo os efeitos dessa prática, em algumas situações os professores - principalmente Vânia - procuravam alterar essa lógica (de só os meninos brincarem do lado de fora da sala), mudando as crianças de lugar. Hoje, por exemplo, a professora pediu minha ajuda para levar os brinquedos do cantinho da casinha (geladeira, fogãozinho, panelinhas, dentre outros) para o lado de fora. Após a mudança, observamos, sem dizer nada às meninas; esperando a reação delas. Percebemos que as meninas brincaram durante quase todo o tempo em sala, sem questionar a ausência do fogãozinho e da geladeira. Elas improvisaram outros enredos que não dependessem desses brinquedos, tanto que nesse dia brincaram quase todas, com bonecas. Somente ao final do horário dos cantinhos, ao perceberem que a geladeira e o fogãozinho estavam no corredor, elas pediram à professora para brincar lá fora. Teoricamente, os meninos não iriam para o corredor, uma vez que a brincadeira de carrinhos aconteceria dentro da sala em função da mudança realizada pela docente. Em dado momento, sem pedir autorização ou avisar a professora, um grupo de meninos sai da sala e vai brincar no corredor. Ao contrário das meninas que estão todas agrupadas no cantinho da casinha, os meninos ficaram brincando de perseguição (polícia e ladrão) cruzando toda extensão do corredor dando gargalhadas altas, gritando e fazendo uma grande algazarra (Notas do caderno de campo, 7 de maio de 2015).

Esse episódio é marcante em função de que apresenta não só a percepção da professora sobre as diferentes apropriações que meninos e meninas faziam dos espaços da instituição, mas também sua intervenção nesse processo. Ao perceber que os meninos sempre expandiam suas brincadeiras para além do 
espaço da sala de referência, a professora Vânia propõe uma mudança na situação: leva os brinquedos das meninas para fora como forma de alterar a lógica estabelecida anteriormente - nesse dia, seriam elas que brincariam no corredor. Contudo, a professora não disse isso às meninas e esperou que elas reagissem à modificação do espaço - o que demorou a acontecer. As meninas, mesmo sentindo falta da geladeira e do fogãozinho, não questionaram nem os procuraram, simplesmente construíram outros enredos que não demandassem a utilização desses brinquedos. Somente no fim do horário (após uma delas descobrir que a professora havia os levado para fora da sala), as meninas pediram para brincar com tais brinquedos no corredor.

Observamos que, mesmo com a intenção de romper com a separação entre meninos e meninas no que se refere aos usos dos espaços interno e externo à sala, a estratégia da professora foi a de deslocar os brinquedos sem questionar seus significados no que concerne às relações de gênero. Se a mudança no ambiente favoreceu o uso do espaço externo pelas meninas, o tipo de brincadeira não foi objeto da reflexão no que concerne ao estímulo e ao incentivo aos meninos de brincar com os brinquedos deslocados para o corredor, tampouco no que diz respeito às meninas criarem outras possibilidades de exploração. Ao não atentar para a especificidade dos brinquedos presentes no contexto da sala de referência, a professora, sem se dar conta disso, reforça a divisão sexual entre as crianças ao usá-los como parte da estratégia, ainda que sua intenção fosse a de combater as diferenças de oportunidades de uso dos espaços entre os meninos e as meninas.

Esse episódio é revelador de que, na apropriação e nos usos dos espaços, tempos e materiais da Educação Infantil, meninos e meninas, adultos e crianças, percebem e se utilizam dos espaços de modos distintos. Podemos observar, assim, a importância de que a reflexão sobre os sentidos dos objetos e da construção dos ambientes com as crianças na Educação Infantil considere também seus significados nas relações de gênero.

Isso, entretanto, não quer dizer que as crianças assimilem passivamente as prescrições presentes nas estruturas da instituição de Educação Infantil que têm o gênero como regulador das condutas sociais. Durante a observação participante, foi possível perceber que as crianças, na qualidade de sujeitos ativos, realizavam escolhas a partir de oportunidades presentes nas situações interacionais vivenciadas, principalmente no que se refere à participação de meninos e de meninas no grupo de pares, apesar de a regulação institucional sugerir ou até mesmo prescrever condutas distintas pautadas nas relações de gênero, o que é perceptível nas imagens da Figura 2 a seguir. 


\section{FIGURA 2 - SITUAÇÕES EM QUE AS CRIANÇAS TRANSGRIDEM AS FRONTEIRAS DE GÊNERO IMPOSTAS PELOS BRINQUEDOS}
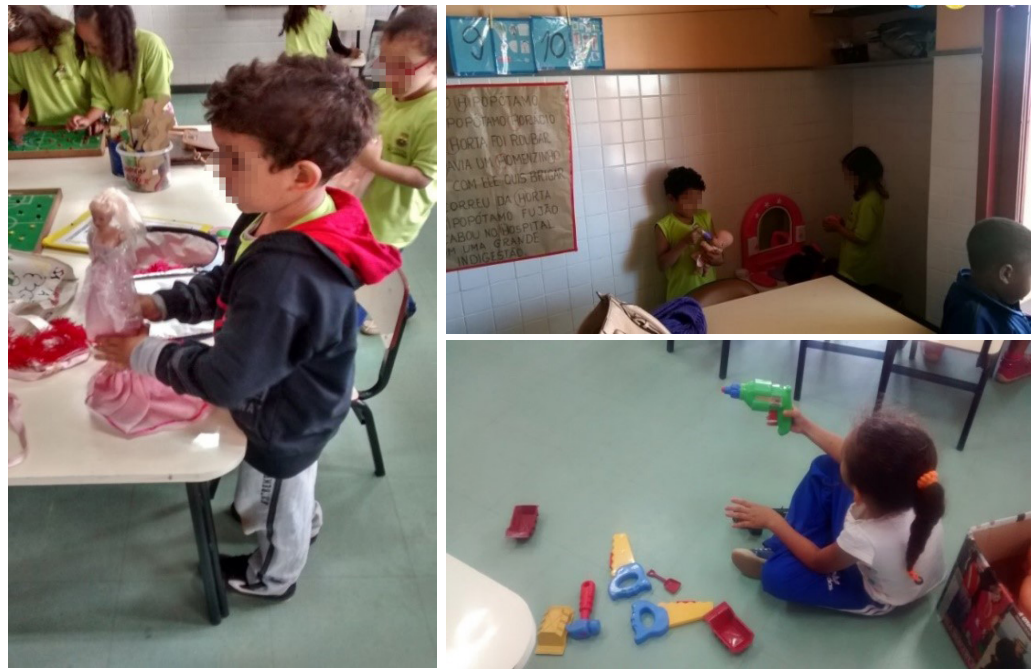

FONTE: Arquivos da pesquisa.

As imagens apresentam momentos que os meninos se propunham experimentar brincar de bonecas enquanto as meninas brincavam com armas e/ou com pebolim ${ }^{5}$. Nesse processo, fica evidente que as estruturas sociais não são apenas condicionantes da ação, mas também possibilitam que as crianças, no momento das interações entre pares, mobilizem dimensões dessa mesma estrutura social durante as brincadeiras, para além das prescrições de gênero (CONNELL; PEARSE, 2015). Isso também foi evidenciado a partir de alguns desenhos produzidos pelas crianças - que, quando articulados com suas falas ${ }^{6}$, possibilitaram-nos não só compreender o processo de apropriação das referências presentes na estrutura de relações sociais que têm no gênero o referente empírico para as condutas de homens e de mulheres, de meninos e de meninas. Outrossim, possibilitou-nos perceber as crianças como sujeitos que têm muito a dizer, em seus próprios méritos, sobre como percebem e se apropriam das relações de gênero.

5 Espécie de jogo de tabuleiro que simula um campo de futebol, com pinos fixos que representam os jogadores. O jogo usa uma espécie de disco que simboliza a bola e é jogado com "petelecos" dados pelos participantes, objetivando o gol adversário.

6 Os desenhos das crianças, quando conjugados com suas falas, se conformam como artefatos relevantes que possibilitam uma maior compressão da produção simbólica infantil, uma vez que se tornam elementos privilegiados de análise em um estudo etnográfico com crianças (PIRES, 2007; SARMENTO, 2011). 
Nos diálogos que seguem, durante a produção dos desenhos, as crianças também demonstraram que, na instituição de Educação Infantil, podiam escolher quais brinquedos utilizar, contrariando, muitas vezes, as normas impostas pelos/ as adultos/as por meio de brinquedos e de brincadeiras indicados para meninos e meninas. Esse é o caso de Andreia Juliane, que, ao desenhar o brinquedo de que mais gostava (Figura 3), afirmou que, apesar de não poder jogar futebol com os irmãos em casa em função de sua mãe a proibir, na escola ela tinha a possibilidade de realizar essa experiência lúdica com os colegas (meninos) da turma. Da mesma forma, os argumentos de Welington, relativos ao desenho por ele produzido (Figura 4) expressam que, embora existam brinquedos para meninos e brinquedos para meninas, estes/as têm na Educação Infantil a possibilidade de escolher com quais brinquedos gostariam de brincar.

\section{FIGURA 3 - DESENHO DE ANDREIA JULIANE}

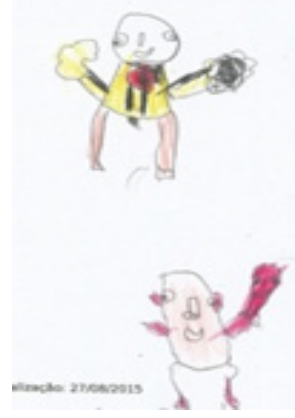

FONTE: Desenhos produzidos pelas crianças.
Pesquisador: - E você acha que existe diferença entre brinquedos de menina e brinquedos de menino?

Andreia Juliane: - Oh, vou te contar um negócio, viu? Minha mãe não gosta que eu fique chutando bola com meus dois irmãos.

Pesquisador: - Por quê?

Andreia Juliane: - Ela fala que não é brincadeira de mocinha!

Pesquisador: - É mesmo?

Andreia Juliane: - Só que aqui na escola eu brinco de chutar bola com os meninos. (Andreia Juliane desenha "O brinquedo que eu mais gosto", 27 de agosto de 2015).

\section{FIGURA 4 - DESENHO DE WELINGTON}

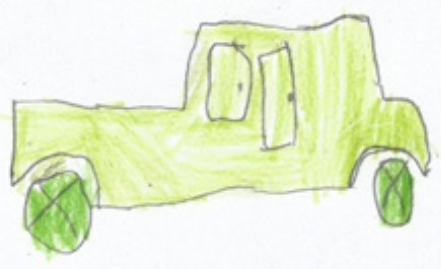

FONTE: Desenhos produzidos pelas crianças.
Pesquisador: - Então, você acha que existem brinquedos para meninos e para meninas? Os brinquedos de meninos e meninas são diferentes? Welington:- São. Meninos brincam de carrinho e meninas brincam de boneca. Mas tem hora que dá pra brincar com tudo. E tem brinquedo que é de menino e de menina. Tipo pecinha [jogos de encaixe].

Pesquisador: - E tem algum tipo de brinquedo que você não gosta de brincar?

Welington: - Não, eu brinco com tudo aqui na UMEI. (Welington desenha "O brinquedo que eu mais gosto", 27 de agosto de 2015). 
Os dados apresentados evidenciam que o mesmo ambiente que reforça representações sobre o masculino e o feminino também possibilita o exercício da crítica, principalmente ao permitir e promover as ações das crianças naquele contexto educativo, que podem viver experiências sociais que permitem que meninos e meninas possam ultrapassar as prescrições e as fronteiras estabelecidas por brinquedos e outras estruturas que, porventura, possam condicionar suas condutas. Isso evidencia a ausência de um debate institucional que promova reflexões constantes em torno das possibilidades reais em que adultos e crianças atuem de modo a construir situações que favoreçam as diferentes formas de vivenciar as masculinidades e as feminilidades (SILVA; LUZ, 2010). Tal processo permitirá às/aos profissionais de Educação Infantil exercitar continuamente o olhar direcionando-o para a própria prática, para as especificidades das crianças e para a influência de sua atuação (pedagógica ou não) junto à agência das meninas e dos meninos.

\section{Considerações finais}

Ao longo deste artigo, buscamos descrever os modos como as crianças produzem sentidos para as relações de gênero vivenciadas (nas interações de pares e com os adultos) no contexto da Educação Infantil, espaço educativo estruturado pelos grandes para os/as pequenos/as. Percebemos que, naquele contexto, as ações cotidianas vivenciadas por adultos/as e crianças (sejam aquelas dotadas de intencionalidade; sejam aquelas menos estruturadas), permitiam a emergência de "[...] práticas e estratégias de organização do dia a dia caracterizadas por uma intencionalidade pedagógica na forma de uma organização institucional que tem no sexo um critério para a organização e o uso dos tempos e dos espaços" (FINCO, 2013, p. 176). Desse modo, torna-se perceptível que, em muitas situações, a regulação estruturante dos adultos/ as/professores/as influencia a ação de meninos e de meninas no processo de escolha e uso que fazem dos espaços da Instituição de Educação Infantil, pois, como vimos nos episódios apresentados, eles se mostram mais expansivos do que elas, que se apresentam de modo mais comedido.

Em diversas situações observadas no momento da empiria, percebemos que as crianças buscavam adequar suas ações às estruturas impostas pela organização dos espaços e pela prática pedagógica, identificadas pela regulação adulta presente no interior da instituição de Educação Infantil. Contudo, cabe esclarecermos que mesmo que as crianças alinhem suas condutas às estruturas 
de gênero impostas pelos adultos, isso não significa que elas sejam passivas aos processos de fabricação de sujeitos gendrados. Ao lançarmos luzes sobre a agência de meninos e de meninas, percebemos que a apropriação das relações de gênero por parte das crianças comporta engajamento e participação ativa deles/as, processo que evidencia possibilidades reais e uma multiplicidade de formas de vivenciar as masculinidades e as feminilidades.

Em síntese, tais considerações permitem discutir que, ao alinhar suas condutas às condições (estruturais) que lhes são oferecidas ou ao subverter, transgredir ou construir formas genuínas de apropriação das relações sociais de gênero, as crianças evidenciam a capacidade social de meninos e de meninas de lerem - no sentido que Geertz (1989 [1973]) confere à expressão: de construir uma interpretação sobre as representações de gênero a partir de um quadro de referências multifacetado, ambíguo e, por vezes, controverso, fato que permite compreender meninos e meninas como sujeitos engajados e comprometidos com a dinâmica societária.

Igualmente, os dados permitem-nos evidenciar a urgência de novos estudos que tomem as crianças como depoentes empíricos capazes de falar, por seus próprios méritos, como sujeitos que produzem sentidos sobre as relações de gênero, ao passo que as vivenciam ativamente.

\section{REFERÊNCIAS}

BUSS-SIMÃO, Márcia. Meninos entre meninos num contexto de educação infantil: um olhar sobre as relações sociais de gênero na perspectiva de crianças pequenas. In: REUNIÃO DAASSOCIAÇÃO NACIONAL DE PÓS-GRADUAÇÃO E PESQUISAEM EDUCAÇÃO, 35., 2012, Porto de Galinhas. Anais eletrônicos [...]. Porto de Galinhas: ANPEd, 2012. Disponível em: http://35reuniao.anped.org.br/images/stories/trabalhos/ GT07\%20Trabalhos/GT07-1364_int.pdf. Acesso em: 10 maio 2016.

BUSS-SIMÃO, Márcia. Relações sociais de gênero na perspectiva de crianças pequenas na creche. Cadernos de Pesquisa, São Paulo, v. 43, n. 148, p. 176-197, jan./abr. 2013.

CARVALHO, Marília Pinto de. O conceito de gênero no dia a dia da sala de aula. Revista de Educação Pública, Cuiabá, v. 21, n. 46, p. 401-412, maio/ago. 2012.

CONNELL, Raewyn; PEARSE, Rebecca. Gênero: uma perspectiva global. Tradução e revisão técnica de Marília Moschkovich. São Paulo: nVersos, 2015.

CORSARO, William A. The sociology of childhood. Thousand Oaks: Pine Forge, 1997. CORSARO, William A. Sociologia da Infância. São Paulo: Artmed, 2011. 
CORSARO, William A.; AYDT, Hilary. Differences in children's construction of gender across culture: an interpretive approach. American Behavioral Scientist, Thousand Oaks, v. 46, n. 10, p. 1306-1325, 2003.

FELIPE, Jane. Estudos Culturais, gênero e infância: limites e possibilidades de uma metodologia em construção. Textura, Canoas, v. 11, n. 19-20, p. 4-13, 2009.

FELIPE, Jane; GUIZZO, Bianca S. Erotização dos corpos infantis na sociedade de consumo. Pro-Posições, Campinas, v. 14, n. 3, p. 119-129, 2003.

FERREIRA, Manuela. O Trabalho de Fronteira nas relações entre géneros em espaços de "brincar ao faz-de-conta". ex aequo, Lisboa, n. 7, p. 113-128, 2002.

FINCO, Daniela. Encontro com as diferenças na educação infantil: meninos e meninas nas fronteiras de gênero. Leitura: Teoria \& Prática, Campinas, v. 31, n. 61, p. 169-184, nov. 2013.

FINCO, Daniela. Relações de gênero nas brincadeiras de meninos e meninas na Educação Infantil. Pro-Posições, Campinas, v. 14, n. 42, p. 89-102, 2003.

GEERTZ, Clifford. A interpretação das culturas. 13. ed. reimpr. Rio de Janeiro: LTC, 1989.

GRAUE, Elizabeth; WALSH, Daniel J. Investigação etnográfica com crianças: teoria, métodos e técnicas. Lisboa: Fundação Calouste Gulbenkian, 2003.

KISHIMOTO, Tizuko M.; ONO, Andréia T. Brinquedo, gênero e educação na brinquedoteca. Pro-Prosições, Campinas, v. 19, n. 3, p. 209-223, 2008.

MAGNANI, José Guilherme C. De perto e de dentro: notas para uma antropologia urbana. Revista Brasileira de Ciências Sociais, São Paulo, v. 17, n. 49, p. 11-29, 2002.

MORROW, Virginia. Understanding gender differences in context: implications for young children's everyday lives. Children \& Society, [s.l.], v. 20, p. 92-104, 2006.

NEVES, Vanessa F. de A. Gênero, sexualidade e Educação Infantil: conversando com mulheres, meninas e meninos. Paidéia, Belo Horizonte, v. 4, p. 147-163, 2008.

PINTO, Mércia de F. N. Regulação e ação pública na política de educação infantil em Belo Horizonte. 2014. 261 f. Tese (Doutorado em Educação) - Universidade Federal de Minas Gerais, Belo Horizonte, 2014.

PIRES, Flávia. Ser adulta e pesquisar crianças: explorando possibilidades metodológicas na pesquisa antropológica. Revista de Antropologia, São Paulo, v. 50, n. 1, p. 225-270, 2007.

ROCHA, Eloisa A. C. Por que ouvir crianças? Algumas questões para um debate científico multidisciplinar. In: CRUZ, Silvia Helena V. (org.). A criança fala: a escuta de crianças em pesquisas. São Paulo: Cortez, 2008.

SALGADO, Raquel G. Da menina meiga à heroína superpoderosa: infầncia, gênero e poder nas cenas da ficção e da vida. Cadernos Cedes, Campinas, v. 32, n. 86, p. 117-136, 2012. 
SANTOS, Sandro V. S. dos. Estrutura e Agência nas Interseções de Gênero e Infância: implicações para a Educação Infantil. Currículo sem Fronteiras, [s.l.], v. 18, n. 1, p. 380-399, 2018.

SANTOS, Sandro V. S. dos. Socialização de gênero na Educação Infantil: uma análise a partir da perspectiva das crianças. 2016. 313 f. Tese (Doutorado em Educação) Universidade Federal de Minas Gerais, Faculdade de Educação, Belo Horizonte, 2016.

SANTOS, Sandro V. S. dos. Socialização de gênero na educação infantil: continuidades e rupturas vivenciadas pelas crianças na família, na igreja e na escola. Educação, Santa Maria, v. 42, n. 3, p. 731-750, 2017.

SANTOS, Sandro V. S. dos; SILVA, Isabel de O. e. Crianças na educação infantil: a escola como lugar de experiência social. Educação e Pesquisa, São Paulo, v. 42, n. 1, p. 131-150, 2016.

SARMENTO, Manuel J. Conhecer a infância: os desenhos das crianças como produções simbólicas. In: MARTINS FILHO, Altino J.; PRADO, Patricia D. (org.). Das pesquisas com crianças à complexidade da infância. Campinas, São Paulo: Autores Associados, 2011.

SAYÃO, Déborah T. Pequenos homens, Pequenas mulheres? Meninos e Meninas? Algumas questões para pensar as relações entre gênero e infância. Pro-Posições, Campinas, v. 14, n. 3, p. 67-87, 2003.

SILVA, Denise R. Q. da; BERTUOL, Bruna. Novos olhares para as pedagogias de gênero na educação infantil. Revista Contrapontos, Itajaí, v. 14, n. 3, p. 448-463, 2014.

SILVA, Isabel de O. e; LUZ, Iza R. da. Meninos na educação infantil: o olhar das educadoras sobre a diversidade de gênero. Cadernos Pagu, Campinas, n. 34, p. 17-39, 2010.

SPRADLEY, James P. Participant observation. New York: Holt, Rinehart and Winston, 1979.

THORNE, Barrie. Gender Play: girls and boys in schools. New Brunswick, NJ: Rutgers University Press, 1993.

WEST, Candace; ZIMMERMAN, Don H. Doing Gender. Gender and Society, [s.l.], v. 1, n. 2, p. $125-151,1987$.

Texto recebido em 31/10/2019.

Texto aprovado em 11/05/2020. 